\section{O Programa de Controle do Dengue em São José do Rio Preto, São Paulo, Brasil: dificuldades para a atuação dos agentes e adesão da população}

\author{
Dengue Control Program in São José do Rio \\ Preto, São Paulo State, Brazil: problems with \\ health agents' work and population adherence
}

\begin{abstract}
This study aimed to identify the aspects that interfere with the performance of vector control agents and community health workers and population adherence to dengue control programs. The focal group methodology was applied to discuss the relations between the program, health agents, and population. According to the results, dengue control and prevention were considered relatively unimportant activities, i.e., ideal community health workers would be capable of solving other (supposedly more important) problems. Vector control agents emphasized the population's lack of adherence and the fact that they (the control agents) were confused with garbage collectors (considered less important than community health workers, and with a focus more on productivity than quality). Women frequently blamed neighbors for the dengue problem and associated the disease with lack of hygiene. These aspects have a negative impact on dengue control agents' work and result from the program's vertical structure. Possible solutions would be to incorporate the agents into community health clinics, encourage cooperation between departments, and provide the conditions for them to intervene in the environment.
\end{abstract}

Dengue; Vector Control; Health Programmes and Projects

\author{
Francisco Chiaravalloti Neto 1,2 \\ Virgínia Baglini 3 \\ Marisa B. Cesarino 4 \\ Eliane A. Favaro 2 \\ Adriano Mondini 2 \\ Aline C. Ferreira 5 \\ Margareth R. Dibo 1 \\ Angelita A. C. Barbosa 2 \\ Amena A. Ferraz 4
}

\section{Introdução}

Após a erradicação do Aedes aegypti do Brasil, o vetor foi reencontrado no Estado de São Paulo em 1985, e em 1990/1991 ocorre a primeira grande epidemia de dengue 1 . Até esse momento as atividades de vigilância e controle do vetor eram executadas pelos funcionários da Superintendência de Controle de Endemias.

A participação dos municípios no controle do dengue iniciou-se, no Estado de São Paulo, com a implantação do Plano de Emergência para o Controle dos Vetores do Dengue e Febre Amarela no verão de 1991/1992. Esse plano realizou o repasse de verbas para que os municípios constituíssem equipes compostas por agentes de controle de vetores para a realização de controle de criadouros 1. O Plano Diretor de Erradicação do Ae. aegypti no Brasil, implantado pelo Ministério da Saúde em 1997, estabeleceu o município como responsável pelo desenvolvimento das atividades de controle do dengue 2 .

Com o fracasso da tentativa de eliminação do Ae. aegypti, o Ministério da Saúde propôs, em 2002, o Plano Nacional de Controle do Dengue, cujas metas são a constituição de equipes municipais específicas para o controle do vetor do dengue e as visitas sistemáticas a todos os imóveis dos municípios infestados 3 . A partir de 2002, os agentes comunitários de saúde do Programa Saúde da Família (PSF) passaram a realizar orientações sobre prevenção e controle do dengue 4 . 
De acordo com as diretrizes do Plano $\mathrm{Na}$ cional de Controle do Dengue, São José do Rio Preto, São Paulo, mantém a Equipe Municipal de Controle do Dengue composta por um grande número de funcionários e de alto custo para a Prefeitura Municipal (Secretaria Municipal de Saúde: dados não divulgados). Apesar da existência dessa estrutura, o dengue continua endêmico no município e apresenta alta incidência 5 - situação idêntica a de muitos municípios brasileiros. Como compreender melhor esta falta de efetividade do programa de controle?

As formas de atuação adotadas não têm contribuído para o aprimoramento das práticas preventivas e a comunidade tem permanecido como espectadora e dependente de ações previamente definidas. Estudos realizados mostraram que o programa tem proporcionado a disseminação de conhecimentos sobre dengue entre a população, sem alterar o quadro da infestação pelo Ae. $a e$ gypti e da transmissão de dengue 6,7 .

As atividades de controle são desenvolvidas verticalmente: não há ligação com o Sistema Único de Saúde (SUS) 8, integração das atividades do setor saúde com os demais setores 9 e fluxo para encaminhamento de demandas. A população reconhece no agente uma porta de entrada para reclamações e requer a resolução de problemas que vão além da presença do vetor e da doença. O hiato entre as demandas e a atuação pública promove o descrédito da população quanto às competências do agente e interfere na sua atuação ${ }^{10}$.

Nesse contexto, os objetivos da pesquisa, com relação aos agentes, foram investigar os obstáculos às ações preventivas do dengue; identificar a inter-relação que estabelecem com supervisores e coordenadores, com o serviço de saúde, demais serviços municipais e com os diferentes estratos sociais da população. Com relação às mulheres da comunidade, o objetivo foi identificar as opiniões e expectativas sobre o trabalho dos agentes e o seu grau de adesão ao trabalho preventivo.

\section{Materiais e métodos}

São José do Rio Preto localiza-se na região noroeste do Estado de São Paulo e, em 2003, contava com uma população de 382.500 habitantes 11, sendo que a área urbana estava dividida em 14 áreas de controle de vetores, onde se realizavam as atividades de controle de criadouros de Ae. aegypti (casa-a-casa), aplicação de inseticidas (pulverização) e visita e controle a locais com grande concentração de criadouros. Nessas áreas atuavam a Equipe Municipal de Controle do Dengue (250 agentes de controle de vetores e 14 supervisores) e 33 agentes comunitários de saúde do PSF, sendo que estes últimos atendiam a $6 \%$ da população.

Tendo por base a triangulação de metodologias e dando continuidade ao estudo quantitativo realizado por Baglini et al. ${ }^{12}$, realizou-se pesquisa qualitativa a fim de buscar a complementaridade entre os instrumentos de pesquisa, captar a complexidade de aspectos no contexto do dengue e obter maior rigor sobre a amostra estudada, sua análise e interpretações. Nessa etapa da investigação, a opção pelo estudo qualitativo trouxe ao universo estudado a possibilidade de identificar o significado e a intencionalidade construídos pelos indivíduos em seu cotidiano, fruto das relações e estruturas sociais nas quais estão envolvidos 13 .

A constituição da amostra se deu a partir da formação de grupos de entrevistados envolvidos nas 14 áreas de controle de vetores, sendo estas divididas em três estratos segundo níveis sócioeconômicos: A (alto), B (médio) e C (baixo). O estrato A englobou as áreas 9, 10 e 14; o B as áreas 6, 7, 8, 11 e 13; e o estrato C as áreas 1, 2, 3, 4, 5 e 12.

Para os agentes, utilizaram-se os seguintes critérios de inclusão: área de atuação conforme estratificação social; tempo de serviço acima de um ano e meio; faixa etária acima dos vinte anos; escolaridade do ensino fundamental incompleto ao médio completo. Para os agentes de controle de vetores, foram realizados três grupos focais, sendo um com agentes que atuavam no estrato A (11 pessoas), um no estrato B (11 pessoas) e um no C (10 pessoas). Para os supervisores dos agentes de controle de vetores foi realizado um único grupo, envolvendo 11 participantes entre 14. Para os agentes comunitários de saúde, foram realizados dois grupos, ambos do estrato $\mathrm{C}$ (por atuarem somente neste estrato), um com $9 \mathrm{e}$ outro com 11 pessoas. Um último grupo foi realizado com os cinco coordenadores do PSF.

Para as mulheres, os critérios de inclusão foram: estratificação social por residência; idade acima de 18 anos e escolaridade entre o ensino fundamental incompleto e o superior completo. Foi composto um grupo de mulheres dos estratos A e B, e outro do estrato $\mathrm{C}$, ambos com seis pessoas.

Os agentes de controle de vetores, agentes comunitários de saúde e mulheres participantes desta amostra foram selecionados aleatoriamente, garantindo que as distribuições da idade e da escolaridade fossem proporcionais às distribuições destas variáveis nos respectivos grupos populacionais, conforme estudo quantitativo realizado anteriormente 12 .

A partir desse universo, em maio de 2003 foram realizados grupos focais $15,16,17$ com reu- 
niões de 1 h e 30min de duração, envolvendo entrevistados e moderador - este, um dos autores do trabalho e responsável pela pesquisa de campo - sendo aplicado um roteiro de entrevista, previamente testado, e elaborado a partir de hipóteses relativas ao contexto de dificuldades enfrentadas pelos agentes em sua atuação e sobre a adesão da população com relação à prevenção do dengue. As falas, gravadas em fitas cassete e transcritas, foram analisadas e interpretadas à luz de técnicas de análise de temas 18,19,20 cujo objetivo foi identificar opiniões, atitudes e crenças elaboradas acerca da relação agente-serviçopopulação, respeitando aspectos recorrentes e singulares presentes na enunciação dos entrevistados e a multiplicidade de sentidos construída a partir daí, e que permitiram traduzir a ação e o posicionamento dos indivíduos frente ao problema ${ }^{14}$. A esta etapa, procedeu-se a construção de três categorias de análise: âmbitos do trabalho, coletivo e particular.

O âmbito particular refere-se à relação imediata que o agente mantém com o morador e à sua participação nas atividades de controle e prevenção no ambiente da casa (intradomicílio e peridomicílio) e adjacências (calçadas e terrenos baldios vizinhos). O âmbito do trabalho contempla organização e condições de trabalho, as relações entre agentes e instâncias superiores e a capacitação profissional. No âmbito coletivo estão identificados os aspectos físico-espaciais e sociais do bairro onde os agentes atuam e o tratamento dado pelo morador aos problemas da coletividade.

Atendendo às exigências do Comitê de Ética em Pesquisa da Faculdade de Medicina de São José do Rio Preto, a pesquisa realizou-se com a assinatura do Termo de Consentimento Informado por todos os participantes, sendo garantido o sigilo dos depoimentos.

\section{Resultados}

\section{Agentes de controle de vetores} e supervisores

\section{- Coletivo}

Os agentes relataram muitas dificuldades disseminadas pelo município, independente de estrato social. Nos bairros de estrato C, a prevenção do dengue concorre com problemas relacionados a altos índices de violência, tráfico de drogas, problemas como a limpeza de terrenos baldios e acesso restrito aos bens públicos: “As pessoas têm problemas financeiros, de saúde, desemprego. E a dengue pra eles é simplesmente mais um pro- bleminha, não tem significado nenhum às vezes". Ainda, “onde há falta d'água, muita gente tem que armazenar em caixas d'água, tambores, então são criadouros constantes de larva".

Nos bairros mais abastados, os problemas enfrentados são: a verificação de casas vazias, de apartamentos fechados e a grande extensão das quadras que comprometem a meta mensal. Nas áreas de chácaras, no estrato $\mathrm{B}$, há terrenos extensos onde as "áreas são muito trabalhosas", com aumento de coleta de criadouros devido à grande extensão do terreno e a dificuldade do morador em eliminar os criadouros. Independente da estratificação, é uma constante no município a existência de terrenos baldios e muitas vezes os agentes são repreendidos pelo morador ao entrarem no domicílio após a vistoria destas áreas: "Você vai pisar na minha casa com aquela terra todinha?", um dos agentes cita um morador.

Agentes e supervisores são unânimes ao afirmarem que a população só aceita o agente se o problema da coletividade for solucionado e reclamam maior agilidade: "A minha cobrança é com relação ao poder público que é responsável pelas ruas, água, esgoto, bueiros entupidos, terrenos públicos. Tem lugar que o morador fala: 'Eu não vou deixar você entrar enquanto não tomar providência e fechar esse buraco!'”.

\section{- Particular}

O principal problema na relação morador-agente é a recusa. Nos bairros mais carentes, a adesão à prevenção fica atrelada à resolução de problemas do morador, como a falta de acesso aos serviços de saúde, ou do bairro: "Às vezes o morador pede pra gente fazer alguma coisa que não corresponde ao nosso trabalho, e se a gente não toma providência fica difícil pra entrar". Na casa, enfrentam problemas com o lixo que se transforma em criadouros. Algumas vezes são vítimas da má vontade do morador e de práticas de atentado ao pudor, tanto feminino como masculino, que constrangem os agentes.

Nos bairros de estratos A e B, a recusa se dá pela desconfiança por roubo, problemas de racismo e a presença constante do serviço na casa. Especialmente nos condomínios de prédios, o problema é a restrição da entrada, obrigando os agentes a se adequar aos horários impostos, o que acarreta pendências. Como solução, os agentes insistem em uma maior divulgação sobre o que cabe a eles e aos moradores realizarem, e a aplicação de medidas punitivas. 


\section{- Trabalho}

Apesar dos agentes concordarem que os problemas devam ser solucionados no âmbito de sua atuação, muitos deles só são resolvidos com a presença do supervisor, por isso solicitam que sua participação seja mais efetiva. Apesar da pouca intervenção do supervisor, quando ocorre, gera resultados positivos na opinião dos agentes: "Quando chega com uma viatura, vem como apoio, aí o morador se sente mais acuado, ou aceita melhor a explicação".

A imagem do agente de controle de vetores tem se perpetuado como catador de lixo, sendo repudiado por eles: "Eu não acho correto catar criadouro do quintal, acho que você tem que educar o morador"; "As pessoas te chamam: 'Ah, quando que você vai passar na minha casa pra pegar o lixo?"'. Os supervisores são partidários dessa crítica: "Eles [os agentes] se revoltam porque estão fazendo uma parte educativa e tudo perde o valor quando eles põem a mão no lixo pra recolher do quintal".

Sobre o sistema de setorização - a fixação do agente numa determinada área - há controvérsias. Parte dos entrevistados é favorável ao sistema: "Há possibilidade de o morador conhecer o agente e daí estabelecer uma relação de confiança". Também auxilia na produtividade e na qualidade do trabalho, entretanto, pode ocorrer cumplicidade entre morador e agente a ponto de prejudicar a vistoria: "Eu defendo não setorizar, eu acho que o morador se acostuma com o agente e vice-versa. Ao passo que tendo um agente diferente toda vez, o morador vai até se interessar pra ver se ele tem alguma coisa nova". Um dos supervisores defende uma situação intermediária com troca anual de agentes: "Dentro de um ano, eu mesmo faço isso. Você faz um cadastro da sua área, eu já sei aquele problema e mudo dentro de um ano, porque até lá você já sabe os problemas [do agente]".

Em relação à possibilidade de assumir novas atribuições, mediante capacitação, os agentes, em princípio, foram receptivos por entenderem como investimento no trabalho e atender melhor as demandas do morador: "Ele [o morador] sempre apresenta alguma dúvida, tem preocupações com outras doenças". Posteriormente alegaram que essa medida poderia gerar acúmulo de atribuições, prejudicar a produção e promover cobrança por parte da chefia. Os supervisores também receiam uma sobrecarga de atribuições: "O agente está no limite, por outro lado o morador já está cansado de ouvir a mesma coisa". Sugerem uma política de incentivo e capacitação: "Como aumento do salário, porque só serviço, só serviço, e o salário, nada?"; "É importante ter um preparo melhor em relação à dengue, um agente mais bem preparado, a conseqüencia é um trabalho mais eficiente".

Sobre a relação agentes de controle de vetores e agentes comunitários de saúde, os primeiros identificaram vários descompassos entre as atribuições, desempenho de tarefas, falta de reconhecimento do trabalho, disparidade entre os salários e diferenciação no treinamento: "Há confusão sobre as diferenças nas atribuições, funções e salário; eles [agentes comunitários de saúde] são mais informação, e nós [agentes de controle de vetores] temos três funções: a teoria, informação e a prática. Eles só informam, mas ganham mais que nós". Os supervisores concordam com a diferenciação: "Eles falam muito do salário porque descobriram que eles ganham melhor!"; “A gente de fora vê a diferença, eles do Programa de Saúde da Família se sentem superiores aos nossos agentes". Entretanto, o vínculo entre o agente comunitário de saúde e o morador é maior e comparado ao sistema de setorização: "Eles podem chamar mais a atenção do morador porque estão mais perto-assim como nós que trabalhamos sob um regime setorizado, sempre em contato com os moradores". De um lado, destacam-se a carga de informações e o empenho no atendimento às famílias, por outro, a crítica corrente é de que o agente comunitário de saúde "não bota a mão na massa".

Os agentes reclamaram da pressão exercida por alguns supervisores no cumprimento da meta de visitas, que é impactado pelas recusas crônicas, casas fechadas, pendências, falta de material ou equipamento quebrado, falhas no canal de comunicação entre poder público e morador. Os supervisores admitem que há uma forte preocupação com a produção: "No dia-a-dia é o que conta, nós temos um teto de produção de 25 casas trabalhadas. Há uma pressão. Porque nós temos que passar pro agente o que a coordenação determinou".

Os agentes apontaram as seguintes necessidades: formação de grupos de discussão sobre os problemas encontrados; aumento do número de agentes; mais esclarecimentos, como por exemplo, sobre a utilização do veneno: "A gente não sabe explicar do que é feito...”. Há críticas sobre o caráter pouco dinâmico das capacitações: "É sempre a mesma coisa, sempre aquele blá, blá, blâ".

\section{Agentes comunitários de saúde e coordenadores do PSF}

\section{- Coletivo}

Nesta esfera, os problemas indicados assemelham-se aos dos agentes de controle de vetores. 
Nas áreas urbanizadas são recorrentes as casas vazias, terrenos baldios, a utilização de lotes para o descarte de lixo e acúmulo de materiais para reciclagem; nas localidades com características rurais existem chácaras com piscinas, sítios e lotes com áreas extensas, onde, muitas vezes, não se consegue identificar o proprietário, o que inviabiliza a vistoria; depósitos de água e bebedouros nas propriedades onde há criação de animais; e no setor industrial o problema está em vistoriar áreas extensas e, em alguns casos, abandonadas.

\section{- Particular}

São duas as principais dificuldades: perda da privacidade quando o agente mora na mesma área onde atua e a necessidade de fazer a visita com hora marcada ou no turno da noite. Com relação ao dengue, as dificuldades estão em vistoriar o banheiro, além da unanimidade em relação à falta de conscientização. A resistência da população em aderir às orientações dadas pelos agentes é confirmada pelos próprios coordenadores.

\section{- Trabalho}

O agente comunitário de saúde é alvo de demandas que não são atendidas por outros setores, tais como autuação e remoção de pontos de ferro velho, que têm processo moroso de encaminhamento; isso gera desmotivação no agente, ansiedade e frustração no morador. Reclamam por um número maior de agentes atuando na área rural e na indústria; pelo cadastramento das chácaras e casas para recreação; pela aplicação de instrumentos de advertência (comunicado e multa); e melhoria das relações de trabalho com os setores que lhes dão suporte. Outra série de dificuldades está relacionada à falta de tempo para o desempenho de todas as funções em razão do número elevado de visitas; necessidade de capacitação profissional para o combate ao dengue; ocorrência de resistência dos moradores em razão da presença constante do serviço; e repetição freqüente das informações.

No repasse das informações, os agentes comunitários de saúde sugeriram revisão dos conteúdos: "Talvez a população não tenha conscientização, porque a propaganda também não seja adequada". Identificaram a ocorrência de informações equivocadas sobre o uso da borra do café e da areia no vaso, e sobre a presença de larva em água suja. Nas visitas, observaram que os moradores relacionam casa limpa com a ausência de larva.

Por fim, os agentes comunitários de saúde reconheceram as dificuldades encontradas pelos seus colegas e sugeriram o fortalecimento do vín- culo entre agente e morador. Um deles concluiu: "Se nós somos os olhos do Programa de Saúde da Família, e a gente às vezes se sente desvalorizado porque também há falta de reconhecimento, imagina com eles?".

\section{Mulheres}

\section{- Coletivo}

Independente do estrato social, as entrevistadas relataram queixas sobre o comportamento de suas vizinhas em relação à falta de higiene e limpeza doméstica: "O quintal lá da vizinha é sujo. A mulher não aceita que os agentes entrem pra fazer visitas de jeito nenhum. A sujeira é demais". Para as mulheres, a atuação fiscalizadora do agente seria a solução do problema: "E graças a Deus que tem os agentes pra fiscalizar, pra pôr medo em certas pessoas"; "Se tem um vizinho que não tem consciência, o mosquito que está lá por culpa dele, vai vir em casa e vai trazer doença aqui pra mim". Do grupo destaca-se uma voz dissonante com uma visão mais integrada entre homem e meio ambiente: "Acredita que a dengue vai acabar? Acho só quando tiver vacina. Porque é uma dinâmica, é o meio ambiente com o ser humano é a interação, meio ambiente com tudo".

\section{- Particular}

A responsabilidade pelos cuidados com a casa, incluindo a ação preventiva do dengue, fica a cargo das próprias entrevistadas, independente do estrato social. Não se observaram, nos grupos, casos de resistência à ação dos agentes, o que, no entanto, foi relatado por estes com um problema freqüente: "Eu acho que hoje em dia realmente as pessoas não fazem porque não querem"; "Lá perto da minha casa só foi resolvido quando a polícia foi". As mulheres fizeram associação entre casa limpa e ausência de criadouros, e relacionaram a falta de higiene e limpeza doméstica com a falta de cuidados com os criadouros e com a existência do mosquito: "Tem gente que não aprende, não quer aceitar uma vida mais limpa, mais dig$n a$ ". Também foram relatadas situações em que ocorre discriminação com relação ao agente: “ $O$ meu patrão fala: '-Ah! Mas, ele entrou aqui dentro? Você deixou ele entrar? Deixou ele sozinho?' Eles ficam com medo deles pegarem alguma coisa, de mexer".

A grande maioria das entrevistadas foi contrária ao rodízio de agentes em suas casas: “Eu gosto de ver sempre a mesma pessoa, e se algum dia houver alguma falsificação de agente, com uniforme?"; "Agora há muita troca, e isso daí acaba também prejudicando. E como o agente fica 
conhecido no bairro, as pessoas diminuem aquele medo". Deu-se preferência pelo agente feminino em razão da segurança, por afinidade, por acreditarem que desempenham melhor o trabalho ou por associarem a mulher aos cuidados da casa: "Eu também prefiro mulher, mulher é mais apropriada, acho que tem a conversa mais aberta”.

As entrevistadas reclamaram das visitas no horário do almoço: "Na minha casa sempre chegam quase na hora do almoço". Quando a visita é realizada fora desse período, não há oposição: "Sempre passam num período bem depois do almoço". E sugeriram visitas com hora marcada: "Seria uma boa sugestão marcar horário para quem não pode receber a visita".

Intensificaram-se as queixas sobre as visitas para aplicação do veneno: "Eu queria saber se o veneno pode atacar a bronquite? Tem gente que fica muito mal. Acho que deveriam conversar mais". Há quem seja favorável ao uso: "Eles traziam um pozinho pra colocar nos pratinhos de xaxim, e não trazem mais. Aquilo era muito bom, ajudava mesmo, porque não dependia da gente".

Foram citadas formas alternativas de prevenção, mas a eficácia é questionada: "Na planta, eu aprendi que tinha que pôr areia ou então evitar que a água ficasse parada. E agora estão falando de borrifar água sanitária na planta!".

\section{- Trabalho}

As entrevistadas apontaram o caráter repetitivo da informação: "Falam sempre a mesma coisa. Eles devem passar outras coisas também. Não tem só o mosquito da dengue, tem o mosquito de cachorro". Sugeriram maior divulgação por meio de veículos de comunicação e estratégias mais agressivas: "Quando tem um problema de dengue num bairro, deveriam abrir a boca, e pôr medo!".

Reclamaram por mais autonomia para os agentes: “... para entrar nas casas fechadas, abandonadas e terrenos baldios e fazer o trabalho da pessoa". Mas identificaram limites impostos à sua atuação: "Sozinho, o agente pode passar informação, fazer a fiscalização, mas tem que chamar alguém pra endossar quando houver resistência ou problemas mais graves".

A aplicação da multa despertou controvérsia. De um lado, como aliada no controle do dengue: "Eu concordo que se aplique multa seja lá para quem for". De outro, duvidou-se de sua eficácia: "O pobre, ele tem medo, ele limpa porque ele não tem dinheiro pra pagar a multa. Agora, e o lado poderoso que são os que têm propriedade e ficam enchendo de lixo?".

\section{Discussão}

Destaca-se a relação que o serviço mantém com a população. Na medida em que o agente se dirige à casa do morador para efetuar o controle epidemiológico, este serviço recebe demandas que, em princípio, destinam-se a outras frentes. Como para a população é imperceptível a divisão de funções e verbas entre os diversos serviços, depreende-se que, para ela, o agente ideal seria aquele capaz de encaminhar as suas demandas. Essa expectativa é utilizada como moeda de troca no controle e prevenção do dengue em suas casas.

As dificuldades de adesão persistem, redundam em recusa e estão disseminadas pelo território independente do estrato social dos bairros. Observa-se que a população considera o controle e prevenção do dengue um serviço de menor importância, o que compromete e desacredita a atuação do agente, cuja imagem perpetua-se como coletor de lixo. Essa relação deixa transparecer o diálogo entre os diferentes estratos sociais e o Estado, e interfere na atitude dispensada pelo morador ao agente. Nos bairros de estratos sociais mais baixos, onde as populações se vêem apartadas de seus direitos essenciais, o dengue tende a caracterizar-se como um problema de menor grandeza aliado à ausência do sentimento de vulnerabilidade diante da doença, que pode ser explicado pela emergência em suprir outras necessidades essenciais. São aspectos também observados no PSF, quando os agentes comunitários de saúde alegam que o trabalho de conscientização concorre com o atendimento às carências imediatas. A marca da municipalidade estampada no uniforme do agente alimenta a percepção no morador de que este é uma porta de entrada para suas demandas. Já nos bairros onde há acesso a bens e equipamentos, tanto público como privado, percebe-se uma atitude de desobrigação por parte dos moradores em participar do processo preventivo.

Em contrapartida, o regime de setorização estabelece maior proximidade entre agente e morador em razão do sentimento de confiança, reforçado pela presença da figura feminina. Isso facilita a realização do trabalho, além do morador acompanhar o seu desenvolvimento.

A proposta de aumento das atribuições dos agentes, que em princípio garantiria maior adesão da população, pode trazer resultados indesejados, como sobrecarregar os agentes, tornando-os ainda mais desacreditados. O sucesso dessa proposta depende do apoio da Secretaria de Saúde e de outros setores da prefeitura - meio ambiente, educação e obras, cuja atuação em conjunto atenderia às demandas da 
população e melhoraria as condições de trabalho dos agentes.

Outro condicionante na atuação do agente é dado pelo binômio produtividade-qualidade, relação raramente equalizada. Apesar das várias opiniões sobre as dificuldades em alcançar tanto uma como outra, a produtividade apresenta, para alguns dos supervisores, peso maior e, no dia-a-dia, se sobrepõe à segunda em razão do cumprimento da meta mensal.

Apesar da atuação conjunta no controle do dengue em algumas áreas do município, a relação agentes de controle de vetores/agentes comunitários de saúde é permeada por conflitos que resultam da diferenciação de status. Os primeiros se ressentem de melhores condições de trabalho, sempre tendo por parâmetro a condição dos agentes comunitários de saúde, sendo o conflito reiterado por estes. Mesmo assim, experiências relatadas pelos agentes comunitários de saúde quanto à forma de atuação poderiam servir de modelo para os agentes de controle de vetores no futuro.

Entre as mulheres entrevistadas confirmouse a relação de culpabilização entre vizinhos, já identificada em outros estudos 10,21,22,23. Isso ocorre independente do estrato social, em que um indivíduo atribui ao outro a causa do problema do dengue, associando-o imediatamente à falta de higiene ou limpeza doméstica, e daí à falta de obediência ao poder público, em primeira instância o agente. Permanece a confusão entre a existência de sujeira e a proliferação de criadouros e de mosquitos, ou mesmo a relação entre casa limpa e ausência de criadouros 10,22,23. Ao mesmo tempo em que as mulheres reivindicaram maior autonomia para os agentes, também pretenderam imputar-lhes atribuições de cunho assistencialista, fiscalizador e punitivo - aspectos criticados pelos agentes e serviços como importantes obstáculos ao caráter educativo da prevenção.

Os aspectos acima destacados, identificados por meio das três categorias de análise (trabalho, particular e coletivo), interferem negativamente na atuação dos agentes de controle de vetores. Aspectos estes condicionados pela falta de intersetorialidade do programa e pela sua característica vertical que, para Hoyos et al. 23 , gera barreiras para a modificação das práticas preventivas na população. A incorporação das atividades de controle do dengue pelo PSF indica uma tentativa de romper com o modelo vertical, mas observa-se que a dimensão intersetorial do controle do dengue não é alcançada mesmo quando é executado pelos agentes comunitários de saúde 4 .

O repasse das atividades de controle do dengue da Superintendência de Controle de Ende- mias, de estrutura vertical, para os municípios, não garantiu que estas fossem implementadas em consonância com os princípios do SUS. Apesar da municipalização, o controle continuou a ser executado da maneira isolada e sem relação direta com a atenção básica e os demais programas de saúde dos municípios.

O Programa de Erradicação do Aedes aegypti reforçou o modelo anteriormente adotado no Estado de São Paulo 2. Apesar de estabelecer o município como o responsável pelo desenvolvimento da maioria das atividades e prever investimentos em saneamento básico e educação, na prática propôs um modelo único de atuação, privilegiou as ações baseadas no controle químico e manteve a atividade com características verticalizadas e sem ligação com o SUS ${ }^{8}$. O Plano Nacional de Controle do Dengue, mesmo com o abandono da idéia da erradicação, tem como metas as visitas sistemáticas a todos os imóveis dos municípios infestados e a constituição de equipes específicas para o controle do vetor ${ }^{3}$. Na prática, ao não vincular esta atividade ao SUS, mantém a estrutura verticalizada dos programas anteriores 8 .

Por outro lado, a incorporação efetiva das práticas preventivas pelo SUS também não é tarefa fácil, pois, segundo Machado \& Porto ${ }^{9}$, o sistema ainda é pautado pelos modelos médico-assistencialista e assistencial-sanitarista, nos quais mantém-se a dicotomia entre promoção e proteção à saúde de um lado e cura de outro. Dessa maneira, as atividades de controle do dengue permanecem desligadas das atividades de saúde do SUS, quer preventiva quer curativa, que por sua vez não mantém relação com as demais áreas governamentais, não havendo, por isso, integração intersetorial. A esse quadro acresce-se o histórico processo de desmonte da estrutura pública de serviços e a falta de investimentos na área social.

O impacto desse quadro no programa de controle do dengue em São José do Rio Preto manifesta-se na manutenção do vetor em altos níveis de infestação (Secretaria Municipal de Saúde: dados não publicados) e na ocorrência endêmica da doença ${ }^{5}$. Uma forma de encaminhamento da questão seria a incorporação dos agentes de controle de vetores às unidades de saúde, a exemplo do que ocorre com os agentes comunitários de saúde, no sentido de horizontalizar o programa e romper a dicotomia entre prevenção e cura. Outro aspecto é que o controle do dengue não pode ser dissociado das políticas sociais de educação, saneamento, habitação e manutenção do espaço público, sendo necessários investimentos na estrutura dos serviços públicos para que ocorra a integração intersetorial e sejam criadas condições para que os agentes atuem sobre os 
problemas do meio ambiente. Há que se ter um canal de comunicação com a comunidade e os trabalhadores da saúde na busca de soluções pa- ra as dificuldades levantadas, além da criação de fluxos para o encaminhamento de demandas e retorno de informações.

\section{Resumo}

O objetivo do trabalho foi identificar aspectos que interferem na atuação dos agentes de controle de vetores e comunitários de saúde no Programa de Controle do Dengue e na adesão da população. Utilizou-se metodologia de grupos focais, nos quais foi discutida a relação agente-serviço-população. O controle e prevenção do dengue foram considerados atividades de menor importância, e o agente ideal seria aquele capaz de encaminhar todas as demandas e não só aquelas relacionadas ao dengue. Os agentes de controle de vetores apontaram para problemas como recusa e falta de adesão, identificação como coletores de lixo, diferenciação de status em relação aos agentes comunitários de saúde. Entre as mulheres, identificaram-se a relação de culpabilização entre vizinhos, a associação do problema do dengue à falta de higiene e a relação entre casa limpa e ausência de criadouros. Os aspectos destacados interferem negativamente na atuação dos agentes e são condicionados pela característica vertical do programa. Encaminhamentos possíveis: incorporação dos agentes de controle às Unidades de Saúde, investimento na integração intersetorial e criação de condições para que os agentes atuem sobre o meio ambiente.

Dengue; Controle de Vetores; Programas e Projetos de Saúde

\section{Colaboradores}

F. Chiaravalloti Neto participou da elaboração do roteiro de entrevistas; seleção, por amostragem, dos participantes; análise e discussão dos resultados. V. Baglini contribuiu com a elaboração e teste do roteiro de entrevistas; como mediadora dos grupos focais; na análise e discussão dos resultados. M. B. Cesarino, E. A. Favaro, A. Mondini, A. C. Ferreira, M. R. Dibo, A. A. C. Barbosa e A. A. Ferraz colaboraram no teste do roteiro de entrevistas; acompanhamento dos grupos focais; transcrição das fitas; análise e discussão dos resultados.

\section{Agradecimentos}

Os autores agradecem aos membros da Equipe Municipal de Controle do Dengue e do Programa Saúde da Família da Secretaria Municipal de Saúde e Higiene de São José do Rio Preto, e às mulheres entrevistadas. 


\section{Referências}

1. Superintendência de Controle de Endemias. Plano de emergência para o controle dos vetores do dengue e febre amarela no verão 1991-1992 no Estado de São Paulo. São Paulo: Superintendência de Controle de Endemias; 1991.

2. Fundação Nacional de Saúde. Plano diretor de erradicação do Aedes aegypti no Brasil. Brasília: Ministério da Saúde; 1996.

3. Secretaria de Vigilância em Saúde. Programa Nacional de Controle do Dengue. Brasília: Ministério da Saúde; 2002.

4. Chiaravalloti Neto F, Barbosa AAC, Cesarino MB, Favaro EA, Mondini A, Ferraz AA, et al. Controle do dengue em uma área urbana do Brasil: avaliação do impacto do Programa Saúde da Família em relação ao programa tradicional de controle. Cad Saúde Pública 2006; 22:987-97.

5. Mondini A, Chiaravalloti Neto F, Sanches MG, Lopes JCC. Análise espacial da transmissão de dengue em cidade de porte médio do interior paulista. Rev Saúde Pública 2005; 39:444-51.

6. Chiaravalloti Neto F, Moraes MS, Fernandes MA. Avaliação dos resultados de atividades de incentivo à participação da comunidade no controle da dengue em um bairro periférico de São José do Rio Preto, São Paulo, e da relação entre conhecimentos e práticas desta população. Cad Saúde Pública 1998; 14 Suppl 2:101-9.

7. Donalisio MR, Alves MJCP, Visockas A. Inquérito sobre conhecimentos e atitudes da população sobre a transmissão do dengue - Região de Campinas, São Paulo, Brasil - 1998. Rev Soc Bras Med Trop 2001; 34:197-201.

8. Santos SL. Avaliação das ações de controle da dengue: aspectos críticos e percepção da população [Dissertação de Mestrado]. Recife: Centro de Pesquisa Aggeu Magalhães, Fundação Oswaldo Cruz; 2003.

9. Machado JMH, Porto MFS. Promoção da saúde e intersetorialidade: a experiência da vigilância em saúde do trabalhador na construção de redes. Epidemiol Serv Saúde 2003; 12:121-30.

10. Chiaravalloti VB, Morais MS, Chiaravalloti Neto F, Conversani DT, Fiorin AM, Barbosa AAC, et al. Avaliação sobre a adesão às práticas preventivas do dengue: o caso de Catanduva, São Paulo, Brasil. Cad Saúde Pública 2002; 18:1321-9.
11. Departamento de Informação e Informática do SUS. Informações demográficas. http://tabnet. datasus.gov.br (acessado em 05/Set/2005).

12. Baglini V, Favaro EA, Ferreira AC, Chiaravalloti Neto F, Mondini A, Dibo MR, et al. Atividades de controle do dengue na visão de seus agentes e da população atendida, São José do Rio Preto, São Paulo, Brasil. Cad Saúde Pública 2005; 21:1142-52.

13. Minayo MCS, Sanches O. Quantitativo-qualitativo: oposição ou complementaridade? Cad Saúde Pública 1993; 9:237-48.

14. Spink MJP. O conceito de representação social na abordagem psicossocial. Cad Saúde Pública 1993; 9:300-8.

15. Krueger RA. Focus groups - a practical guide for applied research. London: Sage Publications; 1994.

16. Pathon MQ. Qualitative evaluation and research methods. London: Sage Publications; 1980.

17. Templeton JF. Focus group - a strategic guide to organizing conduting and analysing the focus group interview. New York: McGraw-Hill; 1994.

18. Bardin L. Análise de conteúdo. Lisboa: Edições 70; 1977.

19. Minayo MCS. O desafio do conhecimento. São Paulo: Editora Hucitec; 2000.

20. Spink MJP. Práticas discursivas e produções de sentidos no cotidiano - aproximações teóricas e metodológicas. São Paulo: Cortez Editora; 1999.

21. Valla VV. Sobre participação popular: uma questão de perspectiva. Cad Saúde Pública 1998; 14 Suppl 2:7-18.

22. Pérez-Guerra CL, Seda H, García-Rivera ED, Clark GG. Knowledge and attitudes in Puerto Rico concerning dengue prevention. Rev Panam Salud Pública 2005; 17:243-53.

23. Hoyos RC, López TT, Villarreal FC, Lucatero AP, González MA, Coutiño BL. Concepciones culturales sobre el dengue en contextos urbanos de México. Rev Saúde Pública 2006; 40:126-33.

Recebido em 06/Jun/2006

Versão final reapresentada em 12/Dez/2006

Aprovado em 12/Jan/2007 